\title{
Marie Barral-Baron
}

Centre Lucien Febvre, Université de Franche-Comté

\section{De l'inspiration au rejet: Renaissance et Réforme}

Artykuł proponuje odmienne podejście do badań nad związkami pomiędzy renesansem a reformacją, rzucając nowe światło na konfrontację poglądów i pism Erazma z Rotterdamu i Marcina Lutra. Okazuje się, iż przebadanie wypowiedzi obu protagonistów prowadzi do odkrycia, że głębokie różnice pomiędzy renesansem a reformacją miały swój początek bardzo wcześnie oraz do ujawnienia, jak dalece idee Lutra redukowały marzenie Erazma o powrocie do „złotego wieku” - mianowicie do zera. W artykule wykazano jednocześnie, że drogi Erazma i Lutra nie rozeszły się, jak często dotąd przyjmowano, nawet w najnowszych badaniach historycznych, w 1524 r., wobec sporu o wolną i niewolną wolę, lecz w rzeczywistości już w 1516 r.

This paper intends to make a fresh start in the study of the relationship between Renaissance and Reformation, by throwing light on the confrontation of both Erasmus and Luther's advances of thought and writings. Actually, studying those two protagonists leads one to find out that the deep differences between Renaissance and Reformation started very early and to underline how much the Lutherian project reduced the Erasmian dream of a return of the Golden Age, to nothing. At the same time, this article reveals that the split between Erasmus and Luther did not take place, as too often asserted, even in the most recent historiography, in 1524, at the time of the conflict between free and servile will, but in fact as soon as 1516 .

Słow a kluczowe: Erazm z Rotterdamu, Marcin Luter, renesans, reformacja, „złoty wiek”, Orygenes z Aleksandrii

Ke yw ords: Erasmus of Rotterdam, Martin Luther, Renaissance, Reformation, Golden Age, Origen of Alexandria 
À lui seul, Érasme incarne la Renaissance, à lui seul Luther symbolise la Réforme. Ces deux hommes sont, l'un comme l'autre, des moines augustins qui ont bu aux mêmes sources patristiques et ont reçu une culture similaire qui les conduit à rechercher un catholicisme très paulinien. Mais le parallèle s'arrête là. Ces deux hommes n'ont pas la même conception du christianisme, le même rapport aux belles lettres et à leur utilité. Si le premier est convaincu que, par la renaissance des lettres, il est possible de retrouver la Tradition première et remédier aux faiblesses de l'Église visible, pour le second le renouveau des lettres et des langues n'est qu'une étape vers la révélation de la Parole de Dieu. Luther se pense comme le Jean-Baptiste qui «prépare la voie». S'arrêter au renouveau, contempler la renaissance des lettres et des arts, comme le fait Érasme, c'est, selon lui, arrêter le mouvement, ne pas laisser épanouir la floraison. Ainsi, si au début Érasme et Luther ont cru se comprendre, ils découvrent peu à peu qu'ils ne partagent ni la même foi ni le même rapport aux studia humanitatis. Tout se passe comme si, pour Luther, la Réforme était le véritable épanouissement de la Renaissance, son réel point de conclusion, alors qu'elle constitue précisément pour Érasme la mise à mort de son rêve humaniste. ${ }^{1}$ Étudier les relations d'Érasme et Luther, c'est découvrir les divergences profondes entre Renaissance et Réforme, les regarder naître l'une de l'autre, grandir côte à côte, puis bientôt se séparer, s'affronter jusqu'à se détruire. La Réforme de Luther anéantit en effet le rêve érasmien de la Renaissance et le combat entre libre et serf arbitre constitue non pas l'hapax de ce duel, comme le présente encore trop souvent l'historiographie du sujet, même la plus récente, ${ }^{2}$ mis la révélation paroxystique de celui-ci. Le kairos entre les deux hommes n'a pas attendu 1524, il a déjà eu lieu en 1516.

I. L'origine d'un lien indéfectible

Le 23 mars 1528, Philippe Melanchthon adresse à Érasme un long courrier dans lequel il lui avoue qu'il déplore autant la trop grande violence du réformateur que l'extrême sensibilité de l'humaniste, laissant percer un souhait qui fut sans doute celui d'un grand nombre: si Luther et Érasme avait pu s'entendre!

${ }^{1}$ L'humanisme est l'expression littéraire et morale de la Renaissance.

${ }^{2}$ Voir l'ensemble des dernières biographies consacrées à Luther, telles celles de L. Roper, Martin Luther. Renegade and prophet (New York, 2017) et H. Schilling, Martin Luther. Rebelle dans un temps de rupture (Paris, 2014) ou encore M. Arnold, Luther (Paris, 2017). 
Ce souhait peut paraître de l'ordre du possible à celui qui regarde rapidement le cheminement de ces deux hommes. Formés, l'un comme l'autre, à seize ans d'écart, chez les Frères de la vie commune, ${ }^{3}$ Érasme à Deventer, Luther à Magdebourg, ils ont grandi dans la tradition de Thomas a Kempis, toute tournée vers la vie intérieure, l'examen de conscience, la lecture de la Bible et la prière. Les Pays-Bas de la jeunesse d'Érasme sont sans nul doute, avec l'Allemagne du temps de l'enfance de Luther, le pays le plus religieux d'Europe. Pour l'essentiel, la sphère d'influence de la Devotio moderna se situe en effet en Hollande, dans le nord de l'Allemagne et dans l'espace rhénan c'est-à-dire au cœur des espaces dans lesquels grandissent Érasme et Luther. Depuis la fin du XIV ${ }^{\mathrm{e}}$ siècle, les associations de clercs et de laïcs pieux se sont multipliées en ces lieux afin de travailler à cette réforme de l'Église et de la société civile dont Gérard Groote a conçu le projet. ${ }^{4}$ C'est en 1478 qu'Érasme entre à l'école capitulaire de Saint-Lébuin, tenue par les Frères de la vie commune à Deventer, en Overijssel. École modeste, les élèves y suivent une règle sévère d'humilité, de renoncement et de perfection monacale. La vie de communauté des Frères est soutenue par la méditation des œuvres de saint Augustin, de saint Bernard, de Ruysbroek et de l'Imitation de Jésus-Christ. Thomas a Kempis désavoue les ambitions hautaines de la scolastique et de la mystique spéculative. Il demeure étranger à tout ce qui est humanisme, haute culture de l'esprit, réconciliation de la pensée antique avec l'Évangile. Son souhait est celui de suivre le Christ qui enseigne la vraie science et accorde aux plus simples la claire intelligence des vérités éternelles. Érasme demeure cinq années dans cette école, de 1478 à 1483 , période assez terne et même triste si l'on donne foi à ce qu'il écrira plus tard. La réalité est sans doute plus complexe. Si c'est dans cette école que le jeune garçon découvre les manuels du Moyen Âge et en prend dégout pour toute sa vie, c'est aussi en ce lieu qu'il suit l'enseignement d'Alexandre Hegius qui

${ }^{3}$ Les Frères de la vie commune sont une des branches de la Devotio moderna née aux Pays-Bas vers la fin du XIV $\mathrm{XI}^{\mathrm{e}}$ siècle et qui essaime en Allemagne au siècle suivant. Si les membres de cette fraternité vivent en communauté, ce ne sont toutefois pas des moines et ils ne prononcent donc pas de vœux perpétuels. Ils font le choix de la pauvreté, mais pas de la mendicité, préférant subvenir à leur existence par le travail. Nombre d'entre eux exercent le métier de copiste et tous mènent une vie simple et humble.

${ }^{4}$ Voir J. Van Engen, Sisters and Brothers of the Common Life. The Devotio Moderna and the World of the Later Middle Ages (Philadelphia, 2008), pp. 11-20. 
lui fait partager son enthousiasme pour la littérature gréco-latine. ${ }^{5}$ Il y rencontre également Rodolphe Agricola, le chantre de l'humanisme aux Pays-Bas. ${ }^{6}$ Des années plus tard, le jeune enfant devenu «prince des humanistes» raconte encore avec ferveur et émotion cette entrevue. Néanmoins, il est certain que l'anti-intellectualisme de la devotio moderna ne convient pas au jeune Érasme dont la curiosité et la soif d'apprendre sont déjà très vives. Les pieuses consolations de l'auteur de l'Imitation de Jésus-Christ appartiennent à une sensibilité différente de la sienne.

À Magdebourg, les Frères s'établissent en 1489 dans le couvent Notre-Dame, où ils fondent officiellement leur maison. Ils n'ouvrent pas d'école eux-mêmes, mais y tiennent sans doute un foyer pour les élèves, ainsi qu'ils ont coutume de le faire dans les villes où ils sont implantés. ${ }^{7}$ Aussi, lorsque Martin Luther ${ }^{8}$ affirme avoir été à l'école chez eux à partir de $1497,{ }^{9}$ cela signifie soit qu'il a eu certains Frères pour maîtres alors qu'il fréquentait l'école de la cathédrale, soit qu'il a été seulement hébergé chez eux, les Frères enseignant très rarement dans les écoles dont ils assument la direction. ${ }^{10} \mathrm{Si}$ la seconde interprétation est la bonne, c'est donc bien à Magdebourg que, pour la première fois, Luther est entré en contact avec un type de communauté quasi monastique. Néanmoins, il est délicat, comme pour Érasme, de mesurer l'influence que la piété des Frères a pu exercer sur lui. Dans ses multiples écrits, il n'évoque pas cette religiosité intériorisée de son enfance, alors qu'il garde un souvenir vif de la piété plus ostentatoire du prince Guillaume d'Anhalt dont il fut le témoin lors de son séjour à Magdebourg. ${ }^{11}$ Il ne demeure d'ailleurs qu'une seule année chez les Frères et, de 1498 à 1501, sans doute pour des raisons familiales, il est envoyé à Eisenach où il fréquente l'école paroissiale

${ }^{5}$ L. E. Halkin, Érasme (Paris, 1987), p. 15.

${ }^{6}$ D. Ménager, Érasme 1469-1536 (Paris, 2003), p. 39.

7 Voir M. Brecht, Martin Luther, T. 1 (Stuttgart, 1981), p. 27.

${ }^{8}$ Le véritable nom de Martin Luther est Martin Luder. C'est seulement à partir de 1517 que Luther commence à signer sous le nom de «Martinus Eleutherius» qui signifie, en grec, l'homme libre, c'est-à-dire Martin le Libéré.

${ }^{9}$ M. Luther, Werke [Weimarer Ausgabe, cité infra: WA]. Abteilung 3: Briefwechsel (Weimar, 1930), infra: WA BR [correspondance], Vol. 1, n 510: 2, 563, 6s (Luther à Claude Storn, bourgmestre de Magdebourg, 15 juin 1522).

${ }^{10}$ C'est la thèse défendue par H. Junghans, Der junge Luther und die Humanisten (Weimar, 1984), p. 63.

11 Arnold, Luther, p. 22. 
Saint-Georges. De l'instruction que Luther a reçue à Magdebourg on ne sait rien, sinon qu'il a sans doute bénéficié d'une solide formation chorale à l'école de la cathédrale.

L'héritage laissé par la devotio moderna n'est donc pas exactement le même chez Érasme et chez Luther, car tout simplement le premier a passé beaucoup plus de temps auprès des Frères que le second. Reste que, en ces écoles, la religion se respire autant qu'elle s'apprend et il est certain qu'Érasme comme Luther ont été élevés au son des hymnes et des cantiques (in hymnis et canticis) et sont deux enfants disposés à la piété, comme l'avoue Érasme lui-même. ${ }^{12}$ Ainsi, le père de la Réforme comme le prince de l'humanisme ont bu aux mêmes sources de la foi.

Leur parenté intellectuelle ne s'arrête pas là, puisqu'ils reçoivent tous deux les ordres et deviennent moines augustins, Érasme à Steyn, Luther à Erfurt. Là encore, ils baignent dans une atmosphère fortement biblique, chaque novice recevant une bible à son entrée au couvent. Mais, alors qu'ils vivent tous deux sous la même règle, qu'ils connaissent le même quotidien, c'est sans doute chez les Augustins que s'épanouissent les premières divergences théologiques et qu'est en germe ce qui empêchera bien plus tard les deux hommes de se comprendre.

La trajectoire des deux jeunes gens s'éloigne en effet lorsqu'Érasme quitte les jardins de l'enfance avec les décès, coup sur coup, de sa mère et de son père en 1483 et 1484 . De ces deuils, il ne dit rien, mais des conséquences de ces disparitions, il en parle abondamment, car c'est un véritable kairos qui surgit dans sa vie. Alors que sa mère l'avait accompagné à l'école de Deventer, s'était installée dans cette cité pendant le temps de sa scolarité, Érasme se retrouve seul, confié à des tuteurs qui l'obligent bientôt à rentrer au couvent. ${ }^{13}$ En 1486 ou 1487, il entre au monastère des chanoines réguliers de Steyn, près de Gouda. Le 25 avril 1492, il est ordonné prêtre. Dès 1493, il quitte le cloître sereinement. De seize ans son cadet, ce n'est que le 17 juillet 1505 que Luther frappe à la porte du couvent des Augustins érémites d'Erfurt, monastère de stricte observance, après avoir étudié à l'université d'Erfurt de 1501 à $1505 .{ }^{14}$ C'est donc par choix,

12 Voir Halkin, op. cit., p. 15.

${ }^{13}$ Il existe plusieurs versions sur cette entrée au couvent, voir Érasme, Euvres choisies, trad. J. Chomarat (Paris, 1991), pp. 150-165.

${ }^{14}$ Arnold, Luther, p. 42; Schilling, op. cit., p. 90. 
réfléchi et assumé, que Luther entre dans les ordres ${ }^{15}$ alors qu'Érasme le fait par obligation. En y séjournant, ce dernier fait la découverte de l'humanisme, tandis que Luther sait déjà qu'il n'est pas humaniste.

Pendant son séjour au monastère, Érasme comprend en effet qu'il n'est absolument pas fait pour la vie selon la cloche et, très vite, il se plonge dans les rayons de la bibliothèque de son couvent. Là, comme il le raconte plus tard, dans cette odeur de vieux papier et de poussière, il découvre le souffle de l'humanisme et comprend ce qu'il veut être. Sa vocation est née, elle ne sera pas monastique. Dès lors, il passe ses journées à lire, pas seulement la Bible et des textes patristiques, mais aussi Térence, qu'il commente, le soir ou la nuit, entouré de quelques condisciples. ${ }^{16}$ Il risque de compromettre sa santé, non pas à cause d'angoisses sur la question de son salut comme Luther quelques années plus tard, mais par l'étude ininterrompue des ouvrages de Lorenzo Valla ${ }^{17}$ ou d'auteurs de l'Antiquité. Il n'est pas inquiet de son péché, il n'est pas torturé par l'angoisse de bien faire son salut, il a simplement peur de ne pas savoir assez car il a un rêve à accomplir, celui de faire renaitre les temps apostoliques. ${ }^{18}$ Pendant les cinq années passées au couvent, Érasme diagnostique les misères du temps présent et la gloire des âges passés et acquiert une culture extraordinaire qu'il ne cessera d'exploiter durant le reste de sa vie. En fait, Érasme accomplit au couvent les découvertes intellectuelles et humanistes que fait Luther à l'université d'Erfurt. Le futur moine de Wittenberg est en effet lui aussi touché par le souffle de l'humanisme pendant sa vie estudiantine. Il manifeste un réel intérêt pour les langues anciennes et pour la rhétorique dont Cicéron, selon lui, est le principal modèle. Il apprécie aussi Térence et Quintilien et, entre 1501 et 1505 , il se familiarise également avec Plaute et Virgile. ${ }^{19}$ Luther, comme Érasme, partage ainsi le même désir de retour au texte originel, la même volonté de restaurer les manuscrits du passé délestés

${ }^{15}$ Heinz Schilling souligne bien ce point en écrivant «le jeune étudiant en droit n'avait pas été obligé à une nouvelle vie par une pression de l'Église romaine, mais à partir d'une contrainte intérieure», Schilling, op. cit., p. 83.

16 Voir A. Hyma, The youth of Erasmus (Ann Arbor, 1930), p. 73.

${ }^{17}$ R. J. Schoeck, "Erasmus and Valla: The Dynamics of a Relationship», Erasmus of Rotterdam Society Yearbook 12, 1992, pp. 45-63. Voir également P. Smith, Erasmus. A Study of His Life, Ideals, and Place in History (New York, 1962), p. 15 .

${ }_{18}$ M. Barral-Baron, L'Enfer d'Érasme. L'humaniste chrétien face à l'histoire (Genève, 2014), p. 33.

19 Junghans, op. cit., p. 83. 
des scories charriés par le passage des siècles. C’est d'ailleurs précisément en cela qu'ils sont, tous deux, hommes de la Renaissance. Ils ont en commun cette joie d'aller boire aux sources des textes. Encore dans la conclusion de son Traité $d u$ serf arbitre, Luther rend grâce à Érasme en ces mots: «Tu m'as rendu de grands services par tes études, et je me reconnais à cet égard ton débiteur, et ton admirateur sincère». ${ }^{20}$ Luther est un grand lecteur d'Érasme, mais si ses écrits attestent combien il connaît bien les classiques, il ne leur confère néanmoins jamais l'autorité qu'il reconnaît à la Bible. Et c'est sans doute là, sur ce point précis, que Luther se détache de l'humanisme. En effet, il y a dans ce courant, derrière l'attirance pour une langue pure et élégante, derrière l'idéal de l'homme trilingue maîtrisant le latin, le grec et l'hébreu, le souci d'éduquer l'être humain pour lui inculquer la sagesse et la foi, censées s'exprimer par l'amour davantage que par la rectitude doctrinale: mieux instruit, l'homme est supposé devenir nécessairement meilleur. Or, même s'il aime les langues anciennes et l'éloquence, Luther ne partage pas cette anthropologie foncièrement optimiste. ${ }^{21}$ Comme le note Matthieu Arnold, Luther ne latinise ni n'hellénise son nom durant ses années à Erfurt, comme il était de mode chez les humanistes. Ce n'est qu'en raison de sa contestation des indulgences, que des années plus tard, Luder deviendra Luther. ${ }^{22}$

Ainsi, lorsque Luther entre au monastère à son tour, il n'est pas dans le même état d'esprit qu'Érasme. Alors que ce dernier place tous ses espoirs en ce courant intellectuel, Luther, qui est d'ores et déjà maître ès Arts, a compris que l'humanisme ne lui suffit pas. Même s'il franchit la porte du couvent avec son édition de Plaute et de Virgile, ${ }^{23}$ il se plonge avidement dans la Bible à la reliure rouge qui lui a été remise à son arrivée. Chaque jour, il étudie les Écritures, chante le livre des Psaumes et lit les écrits de saint Augustin, patron de l'ordre, ceux de saint Bernard de Clairvaux et de Bonaventure. Entré au couvent pour trouver une solution à son angoisse de la mort subite et des fins dernières, il cherche l'apaisement en ses lectures. Moine pieux, exemplaire, "trop bon moine» même écrit Lucien Febvre, ${ }^{24}$ il s'abîme au monastère dans les veilles et les tourments. Alors qu'Érasme recherchait, au fil de ses lectures, la sagesse plutôt que la sainteté, le moine

${ }^{20}$ M. Luther, Du serf arbitre, éd. G. Lagarrigue (Paris, 2001), p. 459.

${ }^{21}$ Arnold, Luther, p. 32.

22 Ibidem.

${ }^{23}$ Schilling, op. cit., p. 105; Arnold, Luther, p. 42.

${ }^{24}$ L. Febvre, Martin Luther, un destin (Paris, 1995), p. 24. 
Luther vise la sainteté plutôt que la sagesse. Il prononce ses vœux définitifs à la fin de l'été 1506 et est ordonné prêtre par l'évêque auxiliaire de Mayence en 1507, sans doute le 3 avril, veille du dimanche des Rameaux. ${ }^{25}$ Néanmoins, le fait d'avoir embrassé la vie conventuelle ne l'empêche nullement de poursuivre son cursus académique. Il achève bientôt ses études de théologie et, fort du grade de bachelier biblique à partir du 9 mars 1509, il commence à enseigner entre Erfurt et Wittenberg.

En 1511, lorsqu'il se rend à Wittenberg, six ans à peine se sont écoulés depuis son admission comme novice chez les Augustins d'Erfurt. Pourtant, le timide étudiant s'est mué en un moine zélé, remarqué et apprécié par le vicaire général de son ordre en Allemagne. Dans cette cité, à côté du cloître, l'Université marque profondément son existence. C'est ici, en 1519, alors qu'il est professeur à l'université de Wittenberg depuis 1513, qu'il découvre comment apaiser son angoisse. Il décrit lui-même, dans une page célèbre en préface à ses Euvres:

Cette année là, j'avais entrepris pour la seconde fois l'interprétation des Psaumes, et je pensais y être mieux préparé, après avoir traité entre temps les Épîtres aux Romains, aux Galates, aux Hébreux dans mes cours. J'avais brûlé du désir de bien comprendre un terme employé dans l'Épître aux Romains, au premier chapitre, là où il est dit: la justice de Dieu est révélée dans l'Évangile. Car jusqu'alors, j'y songeais en frémissant... J'étais hors de moi, tant ma conscience était violemment bouleversée, et je me heurtais sans trêve à ce passage de saint Paul, dans l'ardent désir de savoir ce que saint Paul avait voulu dire. ${ }^{26}$

De quoi s'agit-il? Luther vient de découvrir qu'il n'y a pas d'autre moyen que l'accablement du péché pour connaître l'immensité de la grâce de Dieu. ${ }^{27}$

Ainsi, alors que c'est par son cheminement dans le monastère augustin d'Erfurt que Luther apprend à devenir l'homme de la grâce, c'est dans le monastère augustin de Steyn qu'Érasme comprend son destin d'humaniste. Et, alors que, jusqu'à la fin de sa vie, le sort de Luther est indissolublement lié à celui de la ville et de l'université

25 Y. Krumenacker, Luther (Paris, 2017), p. 83.

${ }^{26}$ Cité par J. Boisset, Érasme et Luther. Libre ou serf arbitre? (Paris, 1962), p. 13.

27 G. Chantraine, «La foi de Martin Luther» (communication présentée lors du cycle de conférences "Recherches et expériences spirituelles», Paris, Notre-Dame de Paris, 5 décembre 1982), pp. 2-11. 
saxonne qu'il ne quittera plus jamais, c'est précisément par la fuite de son couvent qu'Érasme peut débuter sa vie d'homme de la Renaissance et de citoyen du monde. Tel est le service paradoxal rendu par le monastère à l'évolution religieuse d'Érasme. Il lui aura permis de comprendre que l'on peut vivre chrétiennement dans le monde sans craindre d'y sombrer. ${ }^{28}$

\section{De la parenté à la déchirure}

C’est par l'intermédiaire de Georges Spalatin, chapelain et précepteur de Frédéric de Saxe, qu'Érasme entend parler «d'un prêtre de l'ordre de Saint-Augustin» pour la première fois. ${ }^{29}$ Dans une lettre en date du 11 décembre 1516, c'est-à-dire un peu moins d'un an avant que n'éclate au grand jour la protestation du moine saxon contre l'abus des indulgences, Spalatin lui écrit en effet au nom de Luther. Dans ce courrier, il lui fait part, avec d'infinies précautions, des objections que le moine augustin a faites à ses commentaires de saint Paul au sujet des œuvres et du péché originel. ${ }^{30}$ Désormais professeur d'Écriture sainte à l'université de Wittenberg, Luther vient d'achever son commentaire sur l'Épître aux Romains et a en effet relevé des erreurs grossières dans les Annotationes ${ }^{31}$ d'Érasme. «L'Apollon Pythien» (Apollinem Pythium) qu'est devenu l'humaniste ne juge alors pas nécessaire de gâcher du papier et de l'encre pour répondre

${ }^{28}$ Ménager, Érasme, p. 44.

${ }^{29}$ Ce premier échange a été étudié par E.-W. Kohls, «La position théologique d'Érasme et la Tradition dans le 'De libero arbitrio'", dans: Colloquium Erasmianum (Mons, 1968), p. 73. Voir aussi E.-W. Kohls, Luther oder Erasmus: Luthers Theologie in der Auseinandersetzung mit Erasmus, T. 1 (Bâle, 1972), pp. 25-48. C. Augustijn, Erasmus en de Reformatie: een onderzoek naar de houding die Erasmus ten opzichte van de Reformatie heeft aangenomen (Amsterdam, 1962), p. 22, ne débute la préhistoire de la controverse qu'avec la correspondance du mois de mars 1519, lorsque Luther écrit ouvertement à Érasme.

30 Opus epistolarum Desiderii Erasmi Roterodami, éd. P. S. Allen et al. (Oxford, 1906-1958), T. 2 (cité infra: Allen, Opus epistolarum), ép. 501, p. 416, 1. 14-15 (Georges Spalatin à Érasme, Lochau, 11 décembre 1516).

${ }^{31}$ Au moment de la publication de l'édition érasmienne du Nouveau Testament grec, Luther donnait ses cours sur l'épître aux Romains. La publication d'Érasme en mars 1516 tomba alors précisément pendant les vacances semestrielles. Le $1^{\text {er }}$ mai, au commencement du nouveau semestre, Luther a poursuivi la dernière partie de son cours sur l'épître aux Romains avec le chapitre 9. Tout au long de cette dernière partie, il a utilisé l'édition érasmienne. Voir E.-W. Kohls, "Érasme et la Réforme», dans: Colloquia Erasmiana Turonensia, T. 2 (Paris, 1972), p. 845, n 2. 
à ce moine outrecuidant. André Godin écrit avec justesse que «le roi Érasme, exégète consacré par la publication du Novum Instrumentum de 1516, n'avait alors que faire des avertissements d'un obscur confrère de la Saxe profonde!».. ${ }^{32}$ Lorsque ce dernier affiche ses 95 thèses «au sujet de la vertu des Indulgences», à Wittenberg le 31 octobre 1517, Érasme ne s'inquiète pas du retentissement de sa parole, lui qui avouait encore, en 1516, voir l'histoire telle une marée qui flue et reflue, dans laquelle les choses se répètent, événements parfois obscurs dans l'instant, mais dont le sens est au final révélé (Tempus omnia revelat). ${ }^{33}$ C'est d'ailleurs seulement en octobre 1518, dans une épître à Johann Lang, prieur des augustins d'Erfurt, qu'Érasme fait directement allusion à Luther et en termes très laudatifs:

J'entends dire qu'Eleutherius trouve du soutien chez les meilleurs sans exception. Mais on dit aussi que dans ses écrits il ne reste pas égal à lui-même. Je pense que ses fameuses conclusions ont plu à tous, sauf quelques propositions sur le purgatoire: mais ces gens-là désirent absolument qu'on ne vienne pas leur enlever cette vérité qui leur servait de gagne-pain, si l'on peut dire. ${ }^{34}$

À la fin des années 1510, devant les éclats réformateurs de Luther, Érasme ne s'alarme pas, car il croit retrouver chez lui les erreurs condamnées mille ans plus tôt par les Pères de l'Église et les conciles. Ce parallèle confirme d'ailleurs à ses yeux les paroles de l'Ecclesiaste: "Ce qui fut, cela sera, ce qui s'est fait se refera, et il n'y a rien de nouveau sous le soleil!» (Qo 1,9). ${ }^{35}$

En janvier 1519, convaincu que l'humaniste peut apporter son soutien au réformateur, Melanchthon lui adresse une lettre amicale et respectueuse qui s'achève en ces termes:

32 Érasme, éd. C. Blum et al. (Paris, 1992), voir l'introduction à la traduction du De libero arbitrio par A. Godin, p. 685. Voir également A. Godin, «Érasme et Luther d'après leur correspondance: 'Quaestio disputata'?», Mélanges de la Bibliothèque de la Sorbonne 5, 1984, pp. 7-9.

33 L'Adage intitulé Tempus omnia revelat est imprimé dans le recueil des Adages publié en 1500. Il est analysé par P. G. Bietenholz, History and Biography in the work of Erasmus of Rotterdam (Genève, 1966), pp. 19-21.

${ }^{34}$ Cité par J.-C. Margolin, «Érasme et Luther? Erasme ou Luther? Une problématique toujours ouverte», dans: Luther et la Réforme. Du Commentaire de l'Épître aux Romains à la Messe Allemande, éd. J.-M. Valentin (Paris, 2001), p. 208.

35 "Quid est quod fuit? Ipsum quod futurum est. Quid est quod factum est? Ipsum quod faciendum est. Nihil sub sole novum». 
Martin Luther, qui admire grandement ton nom, souhaite ton approbation en toutes choses. ${ }^{36}$

Formule révélatrice de la relation que souhaite instaurer Luther avec celui que l'on ne nomme pas encore le "prince des humanistes»: s'il admire sa personnalité, il ne mentionne cependant pas ses œuvres, et surtout pas ses œuvres religieuses. En 1517, le moine saxon a déjà déclaré: "Je lis notre Érasme et l'aime de moins en moins». ${ }^{37} \mathrm{Il}$ cherche donc à obtenir la caution de l'humaniste, dans ses actes, ses écrits, le contenu de ses thèses, sa conception du péché des hommes et de la grâce de Dieu. En fait, comme l'écrit Jean-Claude Margolin, «il souhaite, avec l'intransigeance du mystique qui pense être le dépositaire de la parole divine, qu'Érasme, son aîné de quatorze ans, jette le poids de son autorité et de sa célébrité dans son entreprise révolutionnaire». ${ }^{38}$ Et il est vrai que Luther a de solides raisons d'espérer que le grand humaniste le soutienne, car ce dernier a porté contre l'Église de sérieuses critiques, moins dans ses dogmes fondamentaux que dans ses aspects institutionnels, ses pratiques et ses rites. Érasme pose très tôt un regard sévère sur les théologiens catholiques, convaincu que ce n'est pas parce que ces derniers sont formés à la scolastique qu'ils sont habilités à définir ce que sont les bonnes œuvres. Au moment du scandale de la vente des indulgences, au cours des années 1510, il s'intéresse aux écrits de Luther et s'oppose comme lui à ce trafic d'âmes. Jusqu'à la confrontation sur le libre arbitre de 1524, Érasme peut même apparaître comme un réformateur, voire comme le précurseur de l'ancien moine d'Erfurt. ${ }^{39}$ Il n'a jusqu'alors pas cessé, notamment dans ses Colloques, ${ }^{40}$ de dénoncer le culte exagéré des saints et la multiplication de leurs images qui les transforment en idoles, tout comme il a critiqué les pèlerinages, l'exploitation et le trafic des indulgences. Il a horreur des théologiens prompts à taxer d'hérétique le moindre de leurs adversaires et se moque du langage barbare des «sophistes» comme des défaillances du monachisme de son temps. Il a également

36 Cité par Margolin, «Érasme et Luther?», p. 209.

37 WA BR, Vol. 1, p. 90, 1. 19-20.

38 Margolin, «Érasme et Luther?», p. 209.

39 Encore en 1525, Noël Béda, théologien de la Sorbonne, lance en pleine séance du parlement de Paris cette accusation: «Les erreurs de Luther [- - ] qui pullulent en ce royaume sont entrées en lui plus par les livres d'Érasme et de Fabry [Jacques Lefèvre d'Étaples] que nuls autres». Voir F. Higman, La Diffusion de la Réforme en France 1520-1565 (Genève, 1992), p. 42.

${ }^{40}$ Voir Érasme, Colloques, trad. et éd. É. Wolff, T. 1-2 (Paris, 1992). 
mis en cause la piété extérieure et, en conséquence, des œuvres que n'inspire pas une foi sincère, critique doublée d'une mise en accusation de la politique mondaine du Vatican et de ses implications anti-évangéliques. Le luxe indécent des prélats italiens est passé aussi sous son crible, tandis que le mariage des prêtres est envisagé sereinement tout comme, comble de la provocation, le débat à propos de l'Eucharistie. En fait, les idées exprimées par Érasme dans l'Enchiridion militis christiani (1503) concordent complètement avec celles développées par Luther au début des années 1520: même forme de piété, de christocentrisme, d'exaltation de l'Évangile, d'intelligence de la lettre et de l'esprit, de mépris du monde. Érasme n'écrit-il pas lui-même:

J'ai composé l'Enchiridion pour guérir l'erreur de ceux qui font consister la religion en cérémonie, en observances judaïques et corporelles et négligent étrangement la vraie piété. L'existence du chrétien ne doit pas être une suite de vaines pratiques, mais une méditation continuelle de l'Écriture, un exercice ininterrompu des vertus qu'elle enseigne [- - ]. Malheureusement, les fidèles ne savent plus que la lettre tue et l'esprit vivifie. ${ }^{41}$

Ces propos d'Érasme témoignent de l'ampleur des points de convergence avec Luther qui est d'ailleurs sans nul doute son meilleur lecteur. Lorsqu'on lit le traité de Luther Contre Latomus (1521), c'est en effet la voix de Dame Folie qui se fait entendre contre le langage forgé par les scolastiques. ${ }^{42}$ La Renaissance semble alors pleinement mère de la Réforme et la filiation est évidente malgré la déchirure. Car si Luther a lu les Colloques d'Érasme et son Éloge de la folie, il a aussi dévoré son Nouveau Testament (1516) et ses éditions patristiques. Le réformateur et ses partisans doivent aux humanistes, et parmi eux à Érasme en premier, non seulement d'avoir pu revenir aux sources hébraïques et grecques de la Bible, mais encore d'avoir pu consulter, en des éditions complètes, les œuvres des Pères de l'Église. Ils partagent tous, hommes de la Renaissance comme hommes de la Réforme, la critique de la fausse piété et plus encore le rejet de la théologie scolastique, au langage marqué par les catégories d'Aristote. Conscient de ce lien, c'est encore en 1524, alors que le moine

${ }^{41}$ Allen, Opus epistolarum, T. 6, ép. 181, p. 405. Voir Desiderius Erasmus Roterodamus ausgewählte Werke, éd. H. Holborn (München, 1933; reprint München, 1964).

${ }^{42}$ Arnold, Luther, p. 358. 
saxon est désormais excommunié (1520) et que l'affrontement avec lui a sérieusement débuté, qu'Érasme lui-même publie un texte soucieux de les réconcilier. Dans son colloque intitulé Inquisitio de fide (Interrogatoire de la foi), il tente en effet, une fois encore, de renouer le dialogue entre catholiques intransigeants et futurs luthériens par le truchement des figures d'Aulus, porte-parole d'Érasme, et de Barbatus, qui représente Luther. ${ }^{43}$ Aulus interroge, tandis que Barbatus répond. Par exemple, à la question "Crois-tu en Dieu le Père tout puissant, qui a crée le ciel et la terre?», ${ }^{44}$ Barbatus répond qu'il entend par Dieu un esprit tout puissant, d'une sagesse admirable et d'une infinie bonté, et qu'il se soumet totalement à lui. Au fil d'un très long interrogatoire, Aulus-Érasme vérifie toute l'orthodoxie de son interlocuteur et, très agréablement surpris par la qualité des réponses, il ne peut s'empêcher de s'exclamer: "Je n'ai pas, pour ma part, quand j'étais à Rome, rencontré de croyants aussi sincères». ${ }^{45}$ Il confie d'ailleurs à Barbatus son incompréhension sur la guerre si violente qui a éclaté entre ce dernier et les orthodoxes, remarque à laquelle Barbatus ne répond pas ou plutôt balaye de la main par un "Demandez-le leur», tout en invitant son interlocuteur à venir prendre une collation chez lui. Ce dialogue évite très habilement toute discussion sur la question des dogmes, des institutions ou des rites, qui font précisément problème, et se concentre sur des points très généraux du christianisme. L'idée d'Érasme est bien de lancer des ponts entre luthériens et catholiques, entre Réforme et Renaissance, et de tenter, encore en 1524, de suturer la robe sans coutures du Christ. Peine perdue, ce dialogue déchaîne la colère des deux parties et est bientôt censuré par la Faculté de théologie de Paris. ${ }^{46}$

Reste que ces citations extraites du Inquisitio de fide montrent bien le lien intime et persistant entre la Renaissance et la Réforme à un moment (1524) où, précisément, plus aucun des protagonistes ne les soulignent. Car en fait les divergences, voire les dissensions, entre Érasme et Luther sont plus nombreuses que les points de convergence, comme le dévoilent, souvent dramatiquement, les années 1520, avec la cristallisation du conflit autour de la question du libre arbitre. Comment en est-on arrivé là?

\footnotetext{
${ }^{43}$ Voir Inquisitio de fide. A Colloquy by Desid. Erasmus (1524), éd. C. R. Thompson (New Haven, 1950).

44 Wolff, op. cit., p. 317.

${ }^{45}$ Ibidem, p. 330.

${ }^{46}$ Margolin, «Érasme et Luther?», p. 212.
} 
Dès le 19 octobre 1516, dans sa célèbre lettre à Georges Spalatin, Luther expose très clairement ce qui fait l'opposition entre ce qu'il considère comme sa position théologique et ce qu'il reconnaît en Érasme comme une position morale. ${ }^{47}$ Il fait remonter son désaccord avec Érasme au fait que l'humaniste suit l'exégèse de Jérôme, ${ }^{48}$ dont il a édité les œuvres, tandis que lui préfere saint Augustin: «Mon dissentiment d'avec Érasme vient de ceci: dans l'interprétation des Écritures, je préfere Augustin à Jérôme dans la mesure où il préfere, lui, Jérôme à Augustin». ${ }^{49}$ Clairvoyant, Luther pressent que l'augustinisme d'Érasme reste superficiel, car il correspond peu aux idéaux, intellectuels et religieux, de l'humaniste. Dans ses Annotations sur l'Épitre aux Romains, Érasme ne cache d'ailleurs pas son peu d'attirance pour Augustin qu'il ne cite que comme référent de culture humaniste pour le bien écrire! ${ }^{50}$ Il n'est, pour lui, ni un guide ni un inspirateur privilégié de son exégèse, surtout que, sur le plan proprement doctrinal, son pessimisme s'accorde mal avec la confiance que l'humaniste place dans le Christ. L'évêque d'Hippone accorde tellement de place à l'action de la grâce dans l'œuvre du Salut qu'Érasme ne voit en effet pas comment il pourrait être enrôlé au nombre des défenseurs du libre arbitre. Le réformateur a en revanche bien saisi la filiation étroite et profonde qui lie Érasme à Origène, père grec qu'il découvre en 1501 auprès du franciscain de Saint-Omer, Jean Vitrier, et dont il devient un admirateur inconditionnel. Érasme ne cesse de lui emprunter les meilleurs éléments de la piété du cœur et de son savoir-faire exégétique. ${ }^{51}$ L'Enchiridion est par exemple constellé de références origéniennes, repérables par la combinaison de l'analyse thématique et d'une sémantique historique appropriée. Cette filiation exaspère Luther qui constate, au fil des éditions érasmiennes, l'affirmation par l'humaniste de l'importance du trio des

47 WA BR, Vol. 1, n 27, p. 25-32. La lettre est écrite en latin.

${ }^{48} \mathrm{Au}$ couvent de Steyn, Erasme est un lecteur assidu et passionné des lettres de saint Jérôme qu'il commente publiquement à l'université de Cambridge en 1511 . Dès 1498, il entreprend une édition et une révision critiques de l'œuvre de saint Jérôme dont il amorce également un commentaire. Il demande sans doute à Josse Bade, en 1512, d'imprimer la correspondance de Jérôme, mais le projet n'aboutit pas. Pour les lettres de Jérôme, voir saint Jérôme, Lettres, éd. J. Labourt, T. 1-8 (Paris, 1949-1963).

${ }^{49}$ Cité par Febvre, op. cit., p. 82.

${ }^{50}$ Cet aspect est souligné par André Godin, dans idem, «Augustin (saint, 354-430)», dans: Érasme, p. lxxvi.

${ }^{51}$ A ce sujet, consulter A. Godin, Érasme, lecteur d'Origène (Genève, 1982), passim. 
pères grecs dans le domaine de la théologie: Origène, Chrysostome et Théophylacte. L'absence d'Augustin, pour qui Luther ressent un profond attachement, témoigne bien plus profondément qu'on ne le souligne habituellement, la scission entre Renaissance et Réforme. En effet, l'essentiel de la théologie du réformateur est déjà exprimé dans son commentaire de l'Épitre aux Romains de 1515-1516, alors qu'il n'a pas encore rompu avec l'Église. Très marqué par ses lectures de l'évêque d'Hippone, Luther y défend l'identification du péché et de la tentation et affirme que l'homme reste pécheur sa vie durant et est donc parfaitement incapable de mériter le bonheur éternel. Rien ne peut effacer en lui les effets du péché originel. Luther balaye ainsi toute la dimension fondamentalement optimiste de l'humanisme et de la Renaissance qu'Érasme tente de porter si haut depuis le début des années 1510. À ses yeux, Érasme est davantage un philosophe qu'un théologien. Agacé par l'éviction d'Augustin dans la liste des meilleurs théologiens et par l'omniprésence de Jérôme et Origène dans l'exégèse érasmienne, Luther espère très tôt avoir un jour l'occasion d'en découdre avec le grand humaniste. Il ne va pas attendre longtemps.

Avec l'affichage à Rome, le 24 juillet 1520, de la bulle Exsurge Domine, la situation se dégrade en effet rapidement entre les deux hommes et, avec eux, c'est tout l'esprit de la Renaissance qui change, s'enrichit certes, mais se rétracte aussi face à l'événement réformateur. Cette bulle, qui arrive à Wittenberg le 3 octobre, condamne 41 propositions tirées des écrits de Luther et laisse 60 jours au moine saxon pour se rétracter sous peine d'être excommunié. Loin de le faire reculer, ce texte stimule encore sa résistance et Luther multiplie alors les écrits fondamentaux pour justifier et éclairer ses positions. ${ }^{52}$ Ainsi, dès juin 1520, dans La papauté de Rome, Luther professe l'abolition de toute hiérarchie ecclésiastique et l'identité spirituelle du plus humble des chrétiens et du plus noble des prélats, rejetant l'Église visible en tant qu'institution purement humaine, la véritable Église étant, selon lui, la chrétienté spirituelle ou intérieure. En août 1520, dans son Appel à la noblesse chrétienne de la nation allemande, il attaque ce qu'il nomme les «trois murs de la Romanité», c'est-à-dire la supériorité de la puissance pontificale sur la puissance civile, le droit exclusif

52 En 1520, Luther publie cinq écrits majeurs dans lesquels il expose les éléments fondamentaux de sa doctrine: $A$ la noblesse chrétienne de la nation allemande, le Prélude sur la captivité babylonienne de l'Église, le traité De la liberté chrétienne, le traité Des bonnes auvres et le traité De la papauté de Rome. Sur Luther et son époque, voir notamment Schilling, op. cit., pp. 204-206. 
du pape sur les conciles et l'exclusivité papale de l'interprétation de l'Écriture. Dans La liberté du chrétien, Luther rappelle ce que doit être le vrai chrétien, un homme entièrement soumis à Dieu et affranchi en même temps de tout ce qui n'est pas Dieu. Face à lui, Érasme défend la philosophia christi, cette philosophie du Christ qu'il confond pratiquement avec sa conception de la théologie qui est toute contenue, selon son propre aveu, dans les sources très pures des Évangiles et des Épîtres de saint Paul..$^{53}$ Cette philosophie est restauration d'une nature humaine créée bonne, affirmation qui s'oppose radicalement à celle de Luther, d'autant plus qu'Érasme reconnaît la possibilité, voire la nécessité, de «christianiser», dans une sorte d'embrassement évangélique, les penseurs de l'Antiquité païenne. C'est tout le sens de l'exclamation du Convivium religiosum: «Sancte Socrates, ora pro nobis!.. ${ }^{54}$ Or, aux yeux de Luther, Érasme donne beaucoup trop d'autorité aux textes des anciens et, de manière très cohérente, Luther renonce d'ailleurs par la suite au latin et abandonne bientôt les païens, quels qu'ils soient, y compris Platon, Aristote et Cicéron. C'est dans cet esprit qu'il faut comprendre aussi sa fameuse apostrophe à la tête d'Érasme: "Du bist nicht fromm!» ("Tu n'es pas pieux!»). ${ }^{55}$

Dans ce contexte de plus en plus violent et tendu, les appels érasmiens à la clémence et à la défense des belles-lettres sont très vite inaudibles. Car toute l'Europe est alors en train de s'embraser. À Louvain et à Liège, les écrits de Luther sont brûlés tandis que, le 17 novembre, le moine saxon lance un appel contre le pape hérétique, ennemi de l'Écriture et de la sainte Église. Le 10 décembre 1520 , il brûle à son tour publiquement, devant les portes de la ville de Wittenberg, la bulle Exsurge Domine avec les Décrétales. Sa pensée est alors définitivement fixée. Le pape est l'Antéchrist. Il l'indique d'ailleurs explicitement dans sa réfutation de la bulle pontificale, intitulée Contre la bulle de l'Antéchrist. La réponse ne se fait pas attendre. Le 3 janvier 1521, Rome promulgue la bulle Decet romanum pontificem qui excommunie Luther et ses partisans. La colère d'Érasme devant ce moine qui jamais ne s'apaise éclate alors dans sa correspondance. La Renaissance cherche un nouveau souffle face à la puissance du mouvement réformateur. Le 16 février 1521, à Nicolas Bérault,

53 Voir J. D. Tracy, "Liberation through the Philosophia Christi. Erasmus as a Reformer of Doctrina (1514-1521)», Lutherjahrbuch 62, 1995, pp. 28-47.

${ }^{54}$ Voir Érasme, Cinq banquets, éd. J. Chomarat, D. Ménager (Paris, 1981), p. 87.

55 Cité par J.-C. Margolin, «Érasme et le libre arbitre», Philosophies de l’humanisme, n $15,2^{\text {ème }}$ série, 2006 , p. 70. 
il s'offusque de cet homme violent qui prétend tout réformer alors que déjà, depuis de nombreux siècles, des hommes ont tenté de corriger les abus de l'Église:

Nul n'ignorait que l'Église est écrasée sous la tyrannie, le cérémonial et d'humaines décisions, dictées par la cupidité. Beaucoup déjà avaient désiré ou médité un remède. ${ }^{56}$

Et, quelques jours après, le 25 février 1521, il confie encore à Nicolas Everard:

Personne ne niait que l'Église fut opprimée par la tyrannie de quelquesuns, et beaucoup déjà y cherchaient un remède. ${ }^{57}$

Et il est vrai qu'il n'y eut sans doute pas, à la fin du Moyen Âge, dans l'esprit des chrétiens, d'autre souci plus constant que celui de réformer l'Église. ${ }^{58}$ Pierre Chaunu remarque que «sur plus de deux siècles, l'Église latine est traversée par des courants de réforme qui débouchent, vers 1500, sur le consensus qui n'est pas celui de la Réforme mais de sa nécessité». ${ }^{59}$ Érasme est ainsi abasourdi par cette Réforme qui ne se propose pas, mais qui s'impose au monde chrétien. Pour lui, ce déchaînement de violences est épouvantable, car il est aux antipodes du message christique qu'il s'efforce lui-même, depuis des années, de transmettre et qu'il croyait enfin pouvoir être vécu. L'âge d'or est en train de devenir un mirage. Luther est en train d'assassiner son rêve, sa lecture de la Renaissance. Dans son épître à Nicolas Everard, il ajoute:

De combien de haines Luther accable les belles-lettres et le christianisme! Il a compromis tout le monde dans son affaire, autant qu'il a pu [- $]$. Maintenant que Luther s'est dressé, il a fait si bien, qu'il a aggravé notre joug et que personne n'ose défendre ses propos, même lorsqu'ils sont sensés. ${ }^{60}$

${ }^{56}$ Allen, Opus epistolarum, T. 4, ép. 1185, p. 444, 1. 19-21 (Érasme à Nicolas Bérault, Louvain, 16 février 1521).

${ }^{57}$ Allen, Opus epistolarum, T. 4, ép. 1186, p. 444, 1. 3-4 (Érasme à Nicolas Everard, Louvain, 25 février 1521).

${ }^{58}$ Sur le sujet, voir F. Rapp, L'Église et la vie religieuse en occident à la fin du Moyen Agge (Paris, 1999), p. 207.

${ }^{59}$ P. Chaunu, Le temps des Réformes (Paris, 1975), p. 11.

${ }^{60}$ Allen, Opus epistolarum, T. 4, ép. 1186, p. 444, 1. 1-6 (Érasme à Nicolas Everard, Louvain, 25 févier 1521). 
Car l'humaniste sent bien, même si c'est encore un peu confus, que le message de Luther n'est pas tout à fait étranger au sien. Nombreux sont ses correspondants qui l'aident d'ailleurs à trouver la filiation. De ce fait, Érasme condamne moins ce que dit Luther que la manière avec laquelle il transmet son message. Au début, le rapport d'Érasme à Luther se crispe ainsi sur un problème de méthode. Le 10 mai 1521, Érasme écrit:

Je suis d'avis que, avant toute chose, il faut éviter la rupture qui, pour tout homme intègre, ne peut être qu'une catastrophe. C'est dans cette conviction qu'il faut savoir, par une sorte de sainte ruse, se plier aux exigences de notre époque, pourvu que ne soit pas compromis le trésor de la Vérité évangélique, Vérité qui pourrait reconstituer la moralité publique en décadence. ${ }^{61}$

Ce propos d'Érasme n'est ni un programme ni un conseil, il exprime un constat. Car, en mai 1521, la rupture de la chrétienté a déjà eu lieu. Après l'excommunication romaine de Luther, prononcée solennellement en janvier 1521, les institutions de l'Empire se sont mises en branle car, selon une tradition juridique vieille de trois siècles, toute décision prononcée par l'Église doit être exécutée par le saint Empire. L'excommunication de Luther doit ainsi obligatoirement s'accompagner de sa mise au ban de l'Empire. Aucune discussion n'est donc normalement possible. Mais le duc de Saxe réclame et obtient de faire convoquer Luther à la Diète de Worms pour faire entendre sa voix devant les États de l'Empire. Les 17 et 18 avril 1521, Luther comparaît donc devant l'empereur Charles Quint et refuse, une nouvelle fois, de se rétracter. À l'heure où l'on rédige l'édit de Worms qui fait de Luther un hors-la-loi, Érasme écrit encore et croit toujours pouvoir éviter le pire pour la chrétienté. Sa missive du 10 mai 1521 s'adresse à Josse Jonas qu'il tente de convaincre d'œuvrer pour la conciliation. Il lui demande d'intervenir notamment auprès de Philippe Melanchthon, dont l'irénisme tranche avec la violence de Luther. Pour le pousser à agir en ce sens, Érasme rappelle les heurts perpétuels de l'histoire de la sainte Église. C'est la preuve historique qui vient ici au secours de l'Église qui chancelle:

Cette Église du Christ, aujourd'hui encore, ramasse dans le même filet les bons et les mauvais poissons, elle est contrainte à garder l'ivraie mêlée au froment; de même les antiques gardiens de la vraie foi attestent que, dans le passé, elle a eu à souffrir de graves défectuosités: coup sur coup,

${ }^{61}$ Ibidem, ép. 1202, p. 493, 1. 284-287 (Érasme à Josse Jonas, Louvain, 10 mai 1521). 
ils se lamentent de l'extrême corruption des mœurs dans les Ordres d'où auraient dû venir les exemples d'une piété sans tâche. Que, jadis aussi, l'Église romaine se soit départie de son zèle pour la pureté évangélique, c'est un fait qu'ont démontré à suffisance Jérôme qui, s'appuyant sur l'Apocalypse, lui a appliqué le nom de Babylone, et après lui, saint Bernard dans les livres qu'il intitula De Consideratione; parmi les modernes, il n'a pas manqué non plus d'auteurs aux noms célèbres qui ont réclamé une réforme générale de la discipline ecclésiastique. ${ }^{62}$

Mais le 26 mai, la sentence tombe. L'édit de Worms met Luther au ban de l'Empire et ordonne la destruction par le feu de tous ses écrits. Après cet édit, Érasme semble se raidir. ${ }^{63}$ Brutalisé par tant de haine et de violence à son endroit, alors qu'il n'a fait que l'appeler à plus de douceur et de modération depuis des années, Érasme est profondément blessé par ce moine saxon qui ne sait pas rester à sa place et attendre de meilleurs jours. En fait, dès le départ, les deux hommes se séparent très nettement dans leur rapport à l'histoire. Alors qu'Érasme replace la contestation de Luther dans le temps long de l'Église et souligne le fait que l'institution ecclésiale a déjà affronté bien d'autres conflits avant celui-ci, Luther et ses disciples assument rapidement la rupture et recherchent dans le passé des explications à cette déchirure et des confirmations de leur identité. Une telle démarche leur permet d'acquérir la dimension du temps historique, où les mutations se produisent au cours de longues durées et dépassent le plus souvent les intentions des individus. ${ }^{64}$ Elle leur donne aussi conscience de l'originalité de leur entreprise et oblige les catholiques à investir le champ de l'histoire, un domaine que le courant humaniste n'avait jusqu'alors pas mis en avant. Dès lors, de chaque côté, la philologie est mise au service de l'histoire: on exhume

${ }^{62}$ Ibidem, ép. 1202, p. 486-487, 1. 10-19 (Érasme à Josse Jonas, Louvain, 10 mai 1521).

${ }^{63}$ Voir ibidem, ép. 1203, p. 570, 1. 1-17 (Érasme à Louis Ber, Louvain, 14 mai 1521). Dans cette épître, Érasme juge très sévèrement l'enlèvement de Luther à la Wartburg qu'il assimile à une fuite. L'humaniste juge très commode de mettre les armes dans les mains de ses ennemis puis, en se retirant de la scène, de les laisser s'exercer sur d'autres. Luther aura connaissance de cette lettre, puisque Spalatin la lui remettra. Il pourra la lire à nouveau pendant l'hiver 1521-1522, puisqu'Érasme la rendra publique en l'éditant dans les Epistolae ad diversos. Elle ne fera qu'accentuer le mépris de Luther pour Érasme. Voir W. Maurer, Kirche und Geschichte, T. 2 (Göttingen, 1970), pp. 388-389.

${ }^{64}$ A. Minerbi Belgrado, L'avènement du passé. La Réforme et l'histoire (Paris, 2004), p. 26. 
les textes du passé, on élabore des critères permettant d'en établir l'origine, la situation chronologique et le degré de crédibilité. ${ }^{65}$ Pour mieux contrer Luther, Érasme exige la contextualisation des textes et modifie donc sa manière de travailler. L'histoire devient un terrain inédit de combats, de conflits théologique et philologique très violents, car au fil des décennies, l'argument historique devient en effet un élément clé du débat théologique. La Réforme, fruit de la Renaissance, oblige cette dernière à repenser ses fondations.

\section{La rupture}

Les rapports d'Érasme et de Luther ne furent jamais intimes. Tous deux savaient parfaitement ce qui les séparait et si Érasme redoutait Luther, ce dernier le méprisait. Luther essaya d'ailleurs très tôt de lancer les hostilités contre le grand humaniste et nombreuses sont les épîtres qui témoignent de ce conflit couvert qui finit par exploser en 1524. Dès 1517 par exemple, dans un courrier à son ami Lang, le moine Luther confie qu'il aime de moins en moins Érasme. Et, précisant sa pensée, il ajoute quelques lignes plus loin qu'il craint que le grand humaniste «ne se fit pas assez ardemment le champion du Christ et de la grâce divine [- - ]. En ces matières, Érasme est bien plus ignorant que Lefèvre d'Étaples. Ce qui est de l'homme l'emporte, en lui, sur ce qui est de Dieu». ${ }^{66}$ Incisif, déjà très précis dans son jugement, Luther poursuit sa critique dans d'autres épîtres, telle celle adressée en 1522 au professeur de Leipzig Gaspard Boerner, dans laquelle il écrit avec rage:

Vous êtes du côté d'Érasme; mais celui-ci en sait moins sur la prédestination que n'en ont su jadis les sophistes de l'école. Je ne crains pas ses coups, car il n'est nullement formidable en ces choses, pas plus du reste qu'en aucun autre point de la connaissance chrétienne. [- - Je sais qui est cet homme, tout comme je connais les complots de Satan. ${ }^{67}$

L'année suivante, dans une lettre adressée à Jean Ecolampade, c'est la même envie d'en découdre qui se fait jour:

Bien que je sente les traits qu'il me décoche, comme il dissimule son inimitié, je feins aussi de ne pas m'apercevoir de son astuce; mais je comprends mieux qu'il ne le pense. Érasme a accompli la chose pour laquelle

${ }^{65}$ Barral-Baron, op. cit., pp. 545-595.

${ }^{66}$ Cité par Febvre, op. cit., p. 82.

67 WA BR, 2, 449 (Luther à Gaspard Boerner, 28 mai 1522). 
il a été appelé. Il a introduit les langues et nous a détournés des études sacrilèges. Il mourra, comme Moïse, dans les campagnes de Moab; car il ne nous conduit pas à ces choses meilleures qui regardent la piété... Il a mis le doigt sur le mal; mais il ne saurait ni nous enseigner le bien, ni nous conduire à la terre promise. ${ }^{68}$

Érasme a connaissance de ces différentes critiques et, s’il est blessé, il refuse néanmoins de céder à la violence:

Luther me traite de misérable, d'homme attaché à la lettre, ignorant des choses chrétiennes. Je me suis réjoui de voir renaître, grâce à lui, la liberté évangélique: j'espérais qu'il céderait aux conseils de la modération. ${ }^{69}$

Cette agressivité ancienne offre une autre approche du conflit entre Érasme et Luther et donc entre Renaissance et Réforme. Cette confrontation ne début pas en effet, comme cela est toujours souligné par l'historiographie sur le sujet, en 1524 avec le débat sur le libre arbitre, mais la Renaissance et la Réforme sont en conflit dès l'origine. 1524 n'est pas l'hapax de leur duel, mais plus exactement la révélation paroxystique de celui-ci. Le kairos a eu lieu dès 1516. Luther ne peut pas supporter la manière dont Érasme touche au Nouveau Testament. Son approche est trop philosophique, origénienne, hiéronymienne. Le manque de piété, l'oubli de l'augustinisme, le trop plein de confiance en l'homme et en la philologie, insupporte le moine de Wittenberg et signe immédiatement leur impossible échange. En dépit des efforts d'Érasme, la pensée de l'humaniste et celle du moine réformateur s'éloignent et se déchirent avant même l'acte de naissance de la Réforme du 31 octobre 1517.

Malgré sa répugnance à entrer «dans l'arène des gladiateurs», ${ }^{70}$ c'est pourtant bien Érasme qui décide finalement de révéler cette guerre couverte et de débuter les hostilités contre Luther en publiant, en septembre 1524, sa Diatribe sive collatio de libero arbitrio. ${ }^{71}$ Habilement, car il a compris le caractère central de la question, il attaque Luther

${ }^{68}$ Cité par F. Kuhn, Luther. Sa vie et son auvre (Neuchâtel et Genève, 1884), p. 128.

${ }^{69}$ Ibidem.

70 Érasme se voit comme un gladiateur: voir Allen, Opus epistolarum, T. 6, ép. 1601, p. 153, 1. 13-14 (Érasme à Guillaume Budé, Bâle, 25 août 1525).

71 A. Godin, dans: Érasme, pp. 683-772. Voir aussi celle donnée par P. Mesnard, Essai sur le libre arbitre (Alger, 1945). On peut aussi consulter la traduction donnée par Peter Macardle et Clarence H. Miller, De libero arbitrio diatribe sive collatio, éd. Ch. Trinkaus et al. (Toronto, 1999, Collected works of Erasmus). 
sur le libre arbitre de l'homme que le réformateur rejette depuis 1516. C'est en particulier le dogme réformateur de la sola gratia et le présupposé qui le fonde, à savoir que tout ce que l'homme entreprend de lui-même pour son salut est péché, que l'humaniste attaque de front. ${ }^{72}$ Luther et, avec lui, Melanchthon dans ses Loci communes de 1521, présentent la thèse de la liberté de la volonté humaine comme une contamination de l'Évangile par la philosophie païenne. Érasme souligne au contraire les liens entre théologie et philosophie, entre raison et foi. Les réformateurs considèrent le libre arbitre comme contradictoire avec la prédestination divine et comme une façon de minimiser l'œuvre de salut du Christ; au contraire, l'humaniste la justifie et la renforce en y voyant «la force par laquelle l'homme peut se tourner vers ou se détourner de celui qui mène au salut éternel de l'âme». ${ }^{73}$ En fait, Érasme reconnaît avec Luther le primat de la grâce, tout en faisant place au sens de l'effort humain, ce que Luther dénie radicalement. Pour le réformateur, il est impossible de renoncer à l'unique et absolue disposition de Dieu sur la grâce, ainsi qu'à l'image négative de l'homme qui en résulte, celle d'un homme existentiellement pécheur. ${ }^{74}$ En sens inverse, l'humaniste continue d'insister sur la responsabilité propre de l'homme comme fondement de son anthropologie positive qui définit l'homme à partir de la raison. Sans libre arbitre ni libre décision, il lui est impossible de penser une responsabilité humaine, que ce soit du point de vue philosophique ou théologique. Alors qu'Érasme avait présenté son essai comme un «entretien ou comparaison du libre arbitre», la réponse de Luther, un an après, est un coup violent contre l'humaniste dès son titre. ${ }^{75} \mathrm{Il}$ s'agit bien d'une "diatribe» et du plus important ouvrage de Luther depuis la guerre des paysans et son mariage, qui paraît en décembre 1525. Même s'il remercie l'humaniste d'avoir bien choisi le sujet:

Je te vante et te loue d'avoir été le seul à traiter l'essentiel du sujet, et de ne pas m'avoir importuné avec des questions étrangères au débat, telles que la papauté, le purgatoire, les indulgences et autres fariboles, avec lesquelles presque tout les autres ont essayé de me prendre au piège. Toi

${ }^{72}$ Voir G. Chantraine, Érasme et Luther, libre et serf arbitre: étude théologique et historique (Paris et Namur, 1981), pp. 267-440.

73 Voir J. Boisset, «Le christianisme d'Érasme dans la Diatribe sur le libre arbitre», dans: Colloquia Erasmiana Turonensia, T. 2 (Paris, 1972), pp. 657-666.

${ }^{74}$ D. C. Steinmetz, Luther in context (Grand Rapids, 2002), pp. 60-62.

${ }^{75} \mathrm{H}$. Humbertclaude, Érasme et Luther. Leur polémique sur le libre arbitre (Paris, 1909). 
seul, tu as vu le nœud de la question, tu l'as vraiment prise à la gorge: du fond du cœur, merci! ${ }^{16}$

il ne l'épargne pas dans cet écrit majeur, passionné, dont le ton et la manière d'argumenter sont aux antipodes du style érasmien:

Rien n'est plus connu et plus habituel chez les chrétiens que l'affirmation. Rejette les affirmations, tu rejettes le christianisme [- - . Permets-nous donc d'être des affirmateurs et de trouver notre joie dans ces affirmations; quant à toi accorde ton approbation aux philosophes sceptiques et académiques, jusqu'à ce que le Christ t'appelle aussi. Le Saint-Esprit n'est pas un sceptique; ce ne sont pas des doutes ou des opinions subjectives qu'il a inscrits dans nos cœurs, mais des affirmations plus certaines et plus fortes que notre vie même et que toute notre expérience. ${ }^{77}$

Plus Luther progresse dans son argumentation, plus le fossé se creuse avec Érasme. Aucun terrain d'entente n'est possible entre les deux hommes. Tout ce qu'Érasme semble vouloir sauvegarder en l'homme, c'est autant que Luther lui reproche violemment de vouloir enlever à la grandeur et à la gloire de Dieu. Tout se passe comme si l'ensemble des divergences doctrinales et humaines qui séparent ces deux hommes s'exacerbent encore un peu plus en étant mises au grand jour. Jamais l'opposition entre Érasme/Origène et Luther/ Augustin n'a été si criante que dans ce combat. À la question «comment un Dieu bon par nature peut-il vouloir le mal?», Origène offre une réponse exégétique adéquate et une anthropologie foncièrement optimiste qui explique qu'Érasme ne cesse de multiplier les emprunts à son Traité des principes. Excédé, mais aussi impressionné par la forte démonstration origénienne d'Érasme, Luther s'emploie passionnément à la démolir. L'outrance de ses propos est révélatrice de son embarras et de l'importance capitale qu'il attache à ce moment du débat. L'antiorigénisme forcené de Luther le conduit à faire preuve de mauvaise foi en déniant toute valeur aux tropes chaque fois qu'ils sont favorables à l'adversaire et, dans le même temps, à leur accorder énormément d'importance chaque fois qu'ils servent sa thèse. ${ }^{78}$ Pour Érasme, ce déchaînement malhonnête de Luther contre Origène traduit à quel point l'anthropologie du réformateur est confuse et mal assumée. Plus que jamais, Érasme hurle à Luther combien «une

\footnotetext{
${ }^{76}$ Luther, Du serf arbitre, p. 459 ou WA 18, 603, 28.

77 WA 18, 605, 32. Voir M. Lienhard, Martin Luther (Paris, 1991), p. 155.

${ }^{78}$ Godin, Erasme, lecteur, pp. 534-535.
} 
seule page d'Origène [lui] apprend plus de philosophie chrétienne que dix d'Augustin». ${ }^{79}$

En fait, le De servo arbitrio est "le coup de fanfare réformateur contre l'illusion optimiste selon laquelle l'homme pourrait atteindre le salut par ses propres actes», ${ }^{80}$ avec le secours inné de la raison et de la capacité à faire le bien. À partir de ce texte, plus personne ne peut dire que les différences entre l'ancienne théologie romaine et la nouvelle théologie évangélique ne sont pas de nature fondamentale. Si les humanistes et les partisans de Rome cherchent une consolation dans la pensée des possibilités humaines de perfectionnement, Luther, lui, trouve la paix de l'âme précisément en désespérant de cette possibilité, parce que dans cet abîme existentiel, et seulement en lui, il peut expérimenter la grâce inexplicable de Dieu. Lorsque l'on envisage à Strasbourg, en 1537, une édition des œuvres complètes du réformateur, il considère comme un «vrai livre», outre le Cathéchisme, uniquement $D u$ serf arbitre. Le dogme luthérien de la volonté serve est intégré aussi bien dans l'Instruction des visiteurs de 1528 que dans la Confession d'Augsbourg de 1530, mais dans la forme adoucie par laquelle l'humaniste Melanchthon «dépasse» le conflit entre Érasme et Luther sans quitter pour autant le terrain de la théologie réformatrice.

Heinz Schilling souligne l'importance du conflit entre Érasme et Luther comme rupture entre l'humanisme et la Réforme. En effet, selon lui, "c'est précisément la destruction de la confiance en soi traditionnelle, légitimée par la théologie, et le 'non' inconditionnel à toute prétention humaine de se sanctifier soi-même qui posèrent les fondements de l'anthropologie des Temps modernes et libérèrent une dynamique qui posa l'Église, l'État et la société sur de nouveaux fondements». ${ }^{81} \mathrm{Or}$, s'il est évident que ce débat met clairement à jour la lutte à mort qui se joue entre la liberté humaine de la Renaissance et la radicale perdition de l'être humain de la Réforme, ce conflit n'est définitivement pas nouveau. La rupture est intervenue bien avant. Depuis 1516, un face à face des plus violents s'est installé entre Érasme et Luther que ce dernier s'ingénie à faire fructifier. Plus la doctrine de la Réforme s'élabore, plus les arguments contre Érasme et la Renaissance sont démultipliés. Avec sa publication sur le libre

\footnotetext{
${ }^{79}$ Allen, Opus epistolarum, T. 2, ép. 844, p. 337, 1. 252-254. Voir Godin, Érasme, lecteur, p. 430.

${ }^{80}$ Schilling, op. cit., p. 427.

${ }^{81}$ Ibidem, p. 428.
} 
arbitre, Érasme cherche d'ailleurs moins à convaincre Luther qu'à rappeler à ses frères chrétiens son attachement à la foi catholique, à la vieille Église romaine en dépit de ses vicissitudes à travers l'histoire. Ce sont ainsi surtout deux visions de l'histoire qui s'affrontent entre la proposition érasmienne d'une refondation en douceur de l'Église et une Réforme luthérienne qui suppose de saper les fondements exégétiques et théologiques de l'institution. ${ }^{82}$ Dans sa Justification contre la lettre déraisonnable de Martin Luther, éditée 1534, Érasme dévoile une dernière fois son souci d'embrasser l'ensemble de l'histoire humaine et que jamais la Renaissance ne renie la Réforme. Son vieil ami Jean Choler lui écrit depuis Augsbourg le 25 mai pour lui confier son incompréhension devant tant d'indulgence:

Mais ce qui m'a surtout déplu dans ta Justification, c'est de te voir écrire que tu n'as jamais cessé d'aimer Luther. Comment t'est-il possible d'aimer Luther qui t’a accusé de tant de griefs atroces et outragé énormément tant et tant de fois? [- ] Mon christianisme à moi ne va pas jusque-là; tu me dépasses de beaucoup par ta patience. ${ }^{83}$

Même si la Réforme a tué son espoir de restaurer les temps apostoliques, Érasme veut l'intégrer dans la grande histoire chrétienne. En dépit des divergences et des ruptures, la Réforme est le fruit de la Renaissance. ${ }^{84}$ Lecture qui n'est définitivement pas celle de Luther qui ne cesse pas, jusqu'à sa mort en 1546, d'attaquer Érasme, cet homme qui a «nui à l'Évangile autant qu'il [a] fait faire des progrès à la grammaire»! ${ }^{85}$ Les Propos de Table abondent en formules féroces contre l'humaniste, notamment «le fameux Érasme est mort à Bâle, sans prêtre, sans prières, bon pour l'enfer», ${ }^{86}$ condamnation sans appel.

Si tenter de déchiffrer les divergences entre Renaissance et Réforme au prisme de la confrontation entre Érasme et Luther est très intéressant,${ }^{87}$ il reste néanmoins qu'il ne faut surtout pas considérer ces

${ }^{82}$ Barral-Baron, op. cit., pp. 415-418.

${ }^{83}$ Allen, Opus epistolarum, T. 10, ép. 2937, p. 392 (Johann Choler à Érasme, Augsbourg, 25 mai 1534).

${ }^{84}$ Philippe Melanchton comme Martin Bucer continueront de correspondre avec Érasme après 1525, en dépit du conflit sur le libre arbitre. Arnold, Luther, p. 370.

${ }^{85}$ Cité par A. Meyer, Étude critique sur les relations d'Érasme et de Luther (Paris, 1909), p. 26.

${ }^{86}$ Cité par A. Godin, dans: Érasme, p. 699.

${ }^{87}$ Voir M. Arnold, «Une impasse historiographique: Érasme contre Luther, une opposition de tempéraments", Revue des sciences religieuses 85, n 1, 2011, pp. 65-76. 
deux figures comme les images inversées de deux médailles, ni comme l'avers et le revers d'une même médaille. Luther et Érasme s'opposent très violemment et catégoriquement sur de nombreux points. Néanmoins, l'humaniste conserve jusqu'au bout une intelligence critique, une capacité d'accueillir la parole de l'autre, une souplesse même sur des sujets brûlants comme celui de l'Eucharistie. Il n'est pas Cajetan ou Eck qui restent très rigoureusement arc-boutés sur leurs certitudes théologiques, ou même Ronsard qui ne veut voir en la Réforme, même si les temps sont alors bien différents, qu'un "Évangile armé». ${ }^{88}$ Jusqu'au bout, et en dépit de tous les désaccords, oppositions et ruptures qu'attestent avec éclat ouvrages et correspondances, ces deux hommes restent liés par leur formation et leur approche des Évangiles, notamment des Épîtres de saint Paul. Mais si ce lien a traversé les siècles, force est de constater combien le dialogue entre Érasme et Luther a achoppé en leur temps. Tragiquement, le rêve érasmien de la Renaissance s'est fracassé contre l'inquiétude de la Réforme.

\section{Bibliographie}

Sources imprimées

Desiderius Erasmus Roterodamus ausgewählte Werke, éd. H. Holborn (München: C.H. Beck, 1933, reprint 1964)

M. Luther, Werke. Kritische Gesamtausgabe (Weimar, 1883-2009; WA: Weimarer Ausgabe; WA BR: Briefwechsel - correspondance)

Opus epistolarum Desiderii Erasmi Roterodami, éd. P. S. Allen, H. M. Allen et H. W. Garrod (Oxford: Clarendon, 1906-1958), T. 1-12

Traductions française et anglaise

Érasme, éd. C. Blum, A. Godin, J.-C. Margolin et D. Ménager (Paris: Robert Laffont, 1992)

Érasme, Cinq banquets, éd. J. Chomarat et D. Ménager (Paris: Vrin, 1981) Érasme, Colloques, trad. et éd. É. Wolff (Paris: Les Belles Lettres, 1992), T. 1-2

Érasme, Euvres choisies, trad. J. Chomarat (Paris: Hachette, 1991)

Érasme de Rotterdam, Essai sur le libre arbitre, trad. et éd. P. Mesnard (Alger: Chaix, 1945)

${ }^{88}$ F. Lestringant, «Ronsard, Prométhée et les protestants», dans: Les fruits de la Saison, éd. P. Terrier, L. Petris, M.-J. Liengme Bessire (Genève, 2000), p. 224. 
Erasmus, De libero arbitrio diatribe sive collatio, trad. P. Macardle et C. H. Miller, éd. Ch. Trinkaus et al. (Toronto: University of Toronto Press, 1999; Collected Works of Erasmus)

Inquisitio de fide. A Colloquy by Desid. Erasmus (1524), éd. C. R. Thompson (New Haven: Yale University Press, 1950)

M. Luther, Du serf arbitre, éd. et trad. G. Lagarrigue (Paris: Gallimard, 2001)

Saint Jérôme, Lettres, trad. et éd. J. Labourt (Paris: Les Belles Lettres, 1949$-1963)$, T. $1-8$

\section{Littérature secondaire}

M. Arnold, Luther (Paris: Fayard, 2017)

M. Arnold, «Une impasse historiographique: Érasme contre Luther, une opposition de tempéraments", Revue des sciences religieuses 85, 2011, n 1 , pp. $65-76$

C. Augustijn, Erasmus en de Reformatie: een onderzoek naar de houding die Erasmus ten opzichte van de Reformatie heeft aangenomen (Amsterdam: H. J. Paris, 1962)

M. Barral-Baron, L'Enfer d'Érasme. L'humaniste chrétien face à l'histoire (Genève: Droz, 2014)

P. G. Bietenholz, History and Biography in the work of Erasmus of Rotterdam (Genève: Droz, 1966)

C. Blum, A. Godin, J.-C. Margolin, D. Ménager, Érasme (Paris: Robert Laffont, 1992)

J. Boisset, «Le christianisme d'Érasme dans la Diatribe sur le libre arbitre», dans: Colloquia Erasmiana Turonensia, T. 2 (Paris: Vrin, 1972), pp. 657-666

J. Boisset, Érasme et Luther. Libre ou serf arbitre? (Paris: Presses Universitaires de France, 1962)

M. Brecht, Martin Luther (Stuttgart: Calwer, 1981-1987)

G. Chantraine, Érasme et Luther, libre et serf arbitre: étude théologique et historique (Paris: Lethielleux; Namur: Presses Universitaires de Namur, 1981)

G. Chantraine, «La foi de Martin Luther» (communication présentée lors du cycle de conférences "Recherches et expériences spirituelles», Paris, Notre-Dame de Paris, 5 décembre 1982), pp. 2-11

P. Chaunu, Le temps des Réformes (Paris: Fayard, 1975)

L. Febvre, Martin Luther, un destin (Paris: Quadrige, Presses Universitaires de France, 1995)

A. Godin, «Érasme et Luther d'après leur correspondance: 'Quaestio disputata'?», Mélanges de la Bibliothèque de la Sorbonne 5, 1984, pp. 7-18

A. Godin, Érasme, lecteur d'Origène (Genève: Droz, 1982)

L. E. Halkin, Érasme (Paris: Fayard, 1987) 
F. Higman, La Diffusion de la Réforme en France 1520-1565 (Genève: Labor et Fides, 1992)

H. Humbertclaude, Érasme et Luther. Leur polémique sur le libre arbitre (Paris: Bloud \& Gay, 1909)

A. Hyma, The youth of Erasmus (Ann Arbor: University of Michigan Press, 1930)

H. Junghans, Der junge Luther und die Humanisten (Weimar: Hermann Bohlaus Nachfolger, 1984)

E.-W. Kohls, «Érasme et la Réforme», dans: Colloquia Erasmiana Turonensia, T. 2 (Paris: Vrin, 1972), pp. 303-311

E.-W. Kohls, Luther oder Erasmus. Luthers Theologie in der Auseinandersetzung mit Erasmus (Bâle: Friedrich Reinhardt, 1972-1978), T. 1-2

E.-W. Kohls, «La position théologique d'Érasme et la Tradition dans le 'De libero arbitrio'", dans: Colloquium Erasmianum (Mons: Centre Universitaire de l'État, 1968), pp. 69-86

Y. Krumenacker, Luther (Paris: Ellipses, 2017)

F. Kuhn, Luther. Sa vie et son xuvre (recopié à partir de l'édition de la librairie Sandoz et Thuillier), T. 2: (1521-1530) (Neuchâtel et Genève: Librairie générale, 1884)

F. Lestringant, «Ronsard, Prométhée et les protestants», dans: Les fruits de la Saison, éd. Ph. Terrier, L. Petris et M.-J. Liengme Bessire (Genève: Droz, 2000)

M. Lienhard, Martin Luther (Paris: Labor et Fides, 1991)

J.-C. Margolin, «Érasme et le libre arbitre», Philosophies de l'humanisme, n $15,2^{\text {ème }}$ série, 2006, pp. 67-85

J.-C. Margolin, «Érasme et Luther? Érasme ou Luther? Une problématique toujours ouverte», dans: Luther et la Réforme. Du Commentaire de l'Épître aux Romains à la Messe Allemande, éd. J.-M. Valentin (Paris: Desjonquères, 2001), pp. 207-228

W. Maurer, Kirche und Geschichte (Göttingen: Vandenhoeck \& Ruprecht, 1970), T. 2, pp. 388-389

D. Ménager, Érasme 1469-1536 (Paris: Desclée de Brouwer, 2003)

A. Meyer, Étude critique sur les relations d'Érasme et de Luther (Paris: Felix Alcan, 1909)

A. Minerbi Belgrado, L'avènement du passé. La Réforme et l'histoire (Paris: Honoré Champion, 2004)

F. Rapp, L'Église et la vie religieuse en Occident à la fin du Moyen Âge (Paris: Presses Universitaires de France, 1999)

L. Roper, Martin Luther. Renegade and Prophet (New York: Penguin Random House, 2017)

H. Schilling, Martin Luther. Rebelle dans un temps de rupture, trad. J.-L. Schlegel (Paris: Salvator, 2014)

R. J. Schoeck, «Erasmus and Valla: The Dynamics of a Relationship», Erasmus of Rotterdam Society Yearbook 12, 1992, pp. 45-63 
P. Smith, Erasmus. A Study of His Life, Ideals, and Place in History (New York: Harper \& Brother, 1923; reprint: New York: Dover Publications, 1962)

D. C. Steinmetz, Luther in Context (Grand Rapids: Baker Academic, 2002)

J. D. Tracy, «Liberation through the Philosophia Christi. Erasmus as a Reformer of Doctrina (1514-1521)», Lutherjahrbuch 62, 1995, pp. 28-47

J. Van Engen, Sisters and Brothers of the Common Life. The Devotio Moderna and the World of the Later Middle Ages (Philadelphia: University of Pennsylvania Press, 2008)

\section{From Inspiration to Rejection: Renaissance and Reformation}

This paper intends to make a fresh start in the study of the relationship between Renaissance and Reformation by throwing light on the confrontation, of both Erasmus and Luther's advances of thought and writings. Both men were Augustinian monks, brought up on the same patristic sources, who received a similar culture which drove them to look for a very Pauline Catholicism. But the parallel ends there. Those two men did not share the same conception of Christianism, the same connection to literature and its utility. The former was convinced that the revival of literature could enable one to find the tradition again and cope with the weaknesses of the visible Church. Whereas the latter considered this faith in the revival of literature and languages highly questionable. He did not approve of the thoroughly optimistic anthropology of humanism. Thereby, if Luther read Erasmus quite early and with great attention, he fostered a deep hatred towards him. As soon as 1517, Luther confessed: "I am reading our Erasmus and appreciate him less and less". Although he tried to obtain the great humanist's support and authority to help him in his revolutionary venture, he had no longer any liking nor any regard for the scholar. Luther well caught the deep and close filiation existing between Erasmus and Origen. This relationship irritated him, more especially as Erasmus did not quote Saint Augustine, a Father of the Church he himself appreciated a lot. The split between those two streams of thought, usually considered to have started in the years 1524-1525, with the controversy about free will, actually bloomed as early as 1516, with the publication of Novum Instrumentum, a true kairos between Erasmus and Luther.

Marie Barral-Baron jest adiunktem na Uniwersytecie Franche-Comté (Francja). Zajmowała się badaniami nad życiem i poglądami Erazma z Rotterdamu, a także zjawiskami życia politycznego i kulturalnego pierwszej połowy XVI w. 
Obecnie poświęca się badaniom nad postaciami ewangelickich humanistów w latach 1536-1562. Wśród jej publikacji jest monografia: L'Enfer d'Érasme. L'humaniste chrétien face à l'histoire (Genève: Droz, 2014), za którą otrzymała Prix Monseigneur Marcel de l'Académie Française.

Marie Barral-Baron is an associate Professor at the University of Franche-Comté (France). She has studied extensively the thought and the life of Erasmus as well as the political and cultural history of the first half of the sixteenth century. Today, she devotes her research to the evangelical humanists from 1536 to 1562 . Among her publications, is L'Enfer d'Érasme. L'humaniste chrétien face à l'histoire (Genève: Droz, 2014; Prix Monseigneur Marcel de l'Académie Française).

E-mail: marie.bbaron@gmail.com 